$\begin{array}{cccc}\text { sciendo } & \text { International Conference KNOWLEDGE-BASED ORGANIZATION } \\ \text { Vol. XXV } & \text { No } 1 & 2019\end{array}$

\title{
STUDY ON THE PREDICTIVE MAINTENANCE OF VEHICLES AND ITS MANAGEMENT USING THE SPECIFIC "KEEP THE MACHINE RUNNING" APPLICATION
}

\author{
Ioan VIRCA, Dorel BADEA \\ "Nicolae Bălcescu" Land Forces Academy, Sibiu, Romania \\ virca_ioan@yahoo.com, dorel.badea@yahoo.com
}

\begin{abstract}
Due to the advanced equipment for diagnosing the components and technical systems of which they are part, the advanced software techniques and applications for the execution, monitoring and maintenance of management, methods, the tendency to develop the type of predictive maintenance is now being generalized. The importance is given by the possibility of processing the determined results, by estimating the tendency of manifestation of the functional parameters and by establishing the moment of the technical interventions for maintaining the equipment/vehicle in the state of availability. The predictive or conditional maintenance, along with the systematic and predictive maintenance, as ways of planning and executing preventive maintenance, has the advantage that the costs of purchasing diagnostic equipment can be offset by the reduced repair costs, as theoretically the major equipment failure will be greatly reduced. The authors do a study on the possibilities of monitoring and driving automotive predictive maintenance using the Keep the Machine the software application Keep the Machine Running. The research method is to investigate the current level of maintenance and the facilities offered by the specific diagnosis and software application, and to integrate the results in order to achieve an efficient maintenance management.
\end{abstract}

Keywords: equipment, reliability, maintenance, management, KMR

1. Short history of the evolution of technical equipment maintenance

The evolution of the maintenance of technical equipment over time has seen different conceptual and execution stages, determined by the constructive conception itself and the technological level of the technical equipment at that time.

For a long period of several centuries, since the appearance of the first weapons and propulsion systems (14th-15th centuries) and until the beginning of the 20th century, the maintenance was considered to be a handicraft type in the sense that operations aimed at maintaining the technical condition or replacing the equipment, without a unitary technical theory that systematically regulates the restoration of the technical state of existing equipment.
With the weapon systems (artillery, engineering, chemical, signals, tanks, vehicles), during the major world conflagrations and in the interwar period, the technical equipments evolved amazingly from a technical point of view, so the maintenance operations aimed at especially the rapid restoration of the technical condition by replacing the damaged assemblies. The huge losses of the technical equipment on battlefields, the teachings and technical conclusions of the two world wars and the confrontations of the next 20-25 years, together with the development of technical sciences, have led to the conception of the theories on the maintenance of equipment or technical systems. One of the promoters of this theory was the Japanese Seiichi Nakajima, 
considered to be the "father" of the total productive maintenance concept (TPM), in 1971, initiating the basics of a maintenance theory that he scaled the three stages of development up to that point:

a) until 1950, Nakajima found that the maintenance was a corrective type, which supposed that the repair of the technical equipment was done when it was defective, and the theory of maintenance was based on technical engineering, wear, defects, material fatigue, etc., without any rhythmically planned actions to restore the technical state. It was the period in which the notion of reliability was laid;

b) between the 1950s and 1970s, Nakajima appreciated that the maintenance was a preventive-planned type which implied continuous maintenance and repair according to their deterioration, and the theory of maintenance was based on more complex concepts of economic engineering, efficiency, lifecycle, based on rigorous maintenance plans. During this period, the theoretical and practical research had the role of developing the technical reliability component;

c) after the $1970 \mathrm{~s}$ and $1980 \mathrm{~s}$, with the massive penetration of industrial electronics in the construction of technical equipment and implicitly the expansion of their knowledge of reliability, as well as the development of production and manufacturing systems, the improvement of the quality theory and the design of technical equipment, the concept of systemic maintenance that leads to a higher level of the entire industrial theory and practice, namely to the concept of total or productive maintenance and implicitly to the development of the operational reliability component.

The information about Nakajima's maintenance evolution stops here. The authors of the present scientific paper consider, in relation to the current technological level, that the maintenance is carried out at a higher level, explained in the following:

d) although the specialized literature and the sources in the field stop here the evolution of maintenance, only in terms of the classification and hierarchy of the stages of evolution, the authors of the present paper consider that a new important stage should be added, characterized by the presence of CAD, CAM, CBM (conditionbased maintenance/maintenance based on real time monitoring) in building, assisting and regulating the operation of the equipment and supervising it during the manufacturing/maintenance processes.

This advanced stage in industrial practice has developed due to the current knowledge of the theory of reliability, cybernetics, industrial electronics, interdisciplinary and transdisciplinary knowledge (mechatronics, terrotechnics, advanced materials etc.), thus determining the type of predictive maintenance that implies the existence of a complex set of sensors, transmitters, electronic control units, actuators, etc., which can assess the evolution and level of the process quantities at the time of the testing. In this new stage the concept of predictable reliability is generalized.

\section{The current stage of monitoring and managing vehicle maintenance using specialized applications}

The evolution of maintenance, classified under paragraph 1, throughout its developmental stages, has used its own types, methods and technologies to solve the technical condition and the availability of the technical equipment, implicitly of the vehicles. Thus, through sets of repairs, maintenance, remote and real-time surveillance, and an electronically assisted diagnosis with the ability to accurately fix and regulate the functional processes, the state of availability and reliability of the equipment could be ensured at normal parameters. The way of monitoring and managing them has also followed an ascendant path, from scripted forms, through first-generation electronic applications to up-to-date software that allows real-time surveillance and transmission of the decision. 
These specialized software systems are currently being used extensively in industrial firms and in the transport and/or maintenance of technical equipment and vehicles.

For exemplification we mention:

a) ManWinWin

b) KMR (Keep the Machine Running)

ManWinWin is a practical software solution for organizing, planning and monitoring maintenance, manufacturing costs, materials, and the concise analysis of maintenance performance indicators.

Keep the Machine Running is also a software application designed to manage the maintenance of technical equipment/vehicles in an organization, giving the personnel in charge the ability to have permanent control over the equipment, the materials, the activities and the costs associated with maintenance.

Both soft wares are performing and effective, but in this paper we will analyze the possibility of conducting and monitoring predictive maintenance with the Keep Machine Running application available to the authors.

\section{Several aspects of predictive maintenance applied to vehicles}

Predictive maintenance is a new approach to maintaining the conditional type maintenance, in the sense that, with the help of a specific apparatus, table no.1 (digital vibrometers, digital multimeters, diagnostic testers and scanners, infrared thermometers, thermal imaging cameras etc.), measurements of the state and process quantities (pressure, temperature, flow, voltage, intensity, vibrations, wear, etc.) can be made periodically during the operation of the equipment and on the basis of the obtained results the evolution of the measured quantities can be appreciated, the limit operating state can be assessed and, implicitly, the moment of the execution of the preventive maintenance before the failure of the components concerned can be estimated.

In the absence of specialized equipment, the estimation of maintenance interventions can also be made on the basis of predicting the reliability of the components or equipment, using calculations of reliability specific to the laws of repartition of defaults used in the estimation of reliability (exponential, normal, log-normal distribution law, Weibull), allowing the estimation of sizes such as time functioning distribution, average good functioning time, failure intensity, etc.

In the case of vehicles, this type of predictive maintenance has appeared and developed in parallel with on-board electronic operating, assistance, supervision, command and diagnosis systems.

The maintenance costs in this case are higher because the diagnostic equipment itself is more expensive than the classical inspection and control equipment, the level of specialization of the maintenance personnel is higher, the consumption of spare parts and related materials may be higher because it is done outside the normal framework.

Predictive maintenance has the advantage of always maintaining the vehicle in a state of operability or availability. From an economic point of view, only work statistics can show consumed budgets and their mathematical evolution. One of the effects of predictive maintenance lies in the fact that there are no major interruptions due to major failures due to the replacement of the foreseen parts (fig. 1).

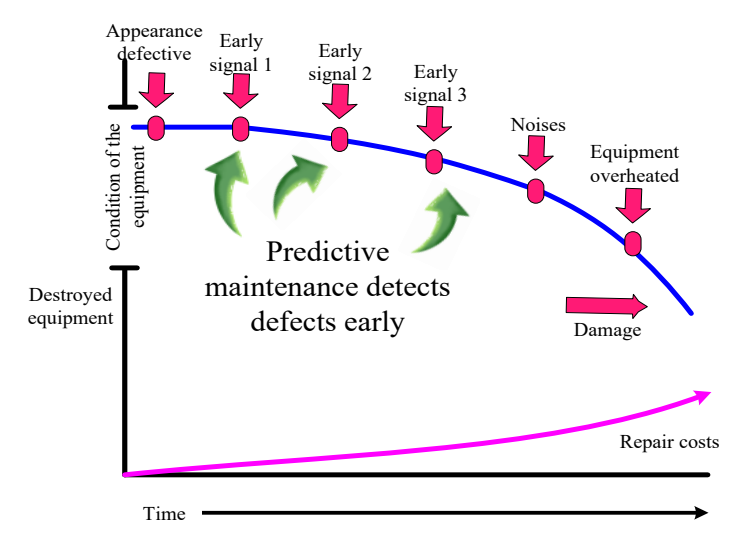

Fig.1. Importance of predictive maintenance 
Table no. 1. Specific predictive maintenance equipment in the field of vehicles

\begin{tabular}{|c|c|c|}
\hline $\begin{array}{l}\text { Name and } \\
\text { type of } \\
\text { apparatus }\end{array}$ & Image of the apparatus & $\begin{array}{c}\text { Characteristics/Facilităţi of the } \\
\text { apparatus }\end{array}$ \\
\hline $\begin{array}{l}\text { Portable digital } \\
\text { vibrometer } \\
\text { Fluke } 805 \mathrm{FC}\end{array}$ & & $\begin{array}{l}\text { Assessing the mechanical problems on a } \\
\text { scale of four levels of gravity } \\
\text { Assessment of vibration level and } \\
\text { technical state in the analysis of the } \\
\text { mechanical problems } \\
\text { Measuring the contactless temperature } \\
\text { with the infrared sensor }\end{array}$ \\
\hline $\begin{array}{l}\text { Digital } \\
\text { multimeter } \\
\text { FLUKE } \\
88 \mathrm{~V} / \mathrm{A}\end{array}$ & & $\begin{array}{l}\text { Measures voltage, current, resistance, } \\
\text { frequency, temperature } \\
\text { Surface for direct reading of } 3,4,5,6,8 \\
\text { engine cylinders } \\
\text { Measures the temperature up to } 999^{\circ} \mathrm{C}\end{array}$ \\
\hline $\begin{array}{l}\text { Digital } \\
\text { multimeter } \\
\text { MD } 9035\end{array}$ & & $\begin{array}{l}\text { Measures the actual voltage and current } \\
\text { value in CC and CA } \\
\text { Measures the capacity and resistivity } \\
\text { The time of the fuel injection } \\
\text { The cycle of impulses }\end{array}$ \\
\hline $\begin{array}{l}\text { Universal } \\
\text { vehicle } \\
\text { diagnosis } \\
\text { scanner } \\
\text { LAUNCH } \\
\text { CR 3001 }\end{array}$ & & $\begin{array}{l}\text { Offers functions of vehicle diagnosis and } \\
\text { carries out protocols, such as ISO } 9141-2, \\
\text { ISO14230-4, SAEJ1850 and ISO15765-4. } \\
\text { You visualize data and flows of graphic } \\
\text { and numeric data } \\
\text { Tests sensors } \\
\text { Function of diagnosis for OBDII/EOBD } \\
\text { vehicle } \\
\text { Compatible with most vehicles }\end{array}$ \\
\hline $\begin{array}{l}\text { Professional } \\
\text { camera of } \\
\text { thermo vision } \\
\text { in infrared } \\
\text { FLIR E95 }\end{array}$ & & $\begin{array}{l}\text { IR thermal imaging, mixing the image in } \\
\text { infrared with the image in visible through } \\
\text { software } \\
\text { Software for analysis of radiometric } \\
\text { images (dynamic images that include } \\
\text { thermal information) and automatic } \\
\text { creation of reports in PDF or DOC format }\end{array}$ \\
\hline $\begin{array}{l}\text { Pistol-type } \\
\text { digital } \\
\text { thermometer } \\
\text { with IR laser } \\
-50^{\circ} \mathrm{C}+420^{\circ} \mathrm{C}\end{array}$ & & $\begin{array}{l}\text { Non-contact digital thermometer, with } \\
\text { infrared (IR laser), allowing the local } \\
\text { determination of the temperature of the } \\
\text { areas heated with the aid of the IR laser, } \\
\text { which accurately focuses the measurement } \\
\text { point }\end{array}$ \\
\hline
\end{tabular}


4. Management of predictive maintenance of vehicles using the "Keep the Machine Running" software application

The Keep the Machine Running (KMR) equipment maintenance application can be used to maintain various objectives (companies, factories, buildings, transport fleets, etc.) in order to efficiently run the human, material and informational resources, reduce the writing of documents and optimize the maintenance activities by assisting them with IT.

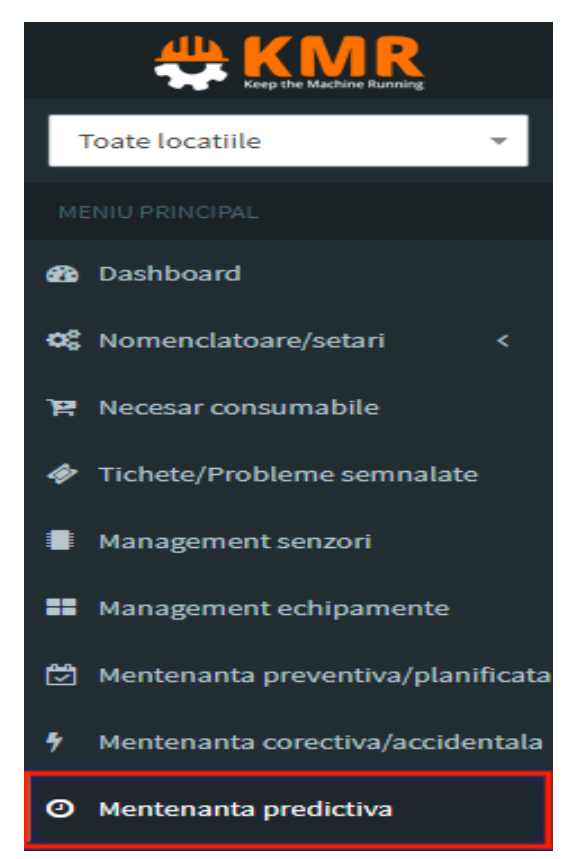

Fig. 2. The meniu of aplication KMR

The main menu of the application (fig. 2) shows all its functions, and all the departments involved in maintenance (procurement, supply, maintenance, energy, accounting, human resources, etc.) relate to each other according to responsibilities.

The menu contains the Predictive maintenance main function, which allows you to plan a predictive review, monitoring the deadlines, and running an application on your mobile phone. If necessary, preventive repairs can be scheduled. The entire flow of material, informational and human resources is run using the other menu functions, including recording all the data. Fig. 3 shows some of the recordings that can be performed with the KMR predictive maintenance function. 


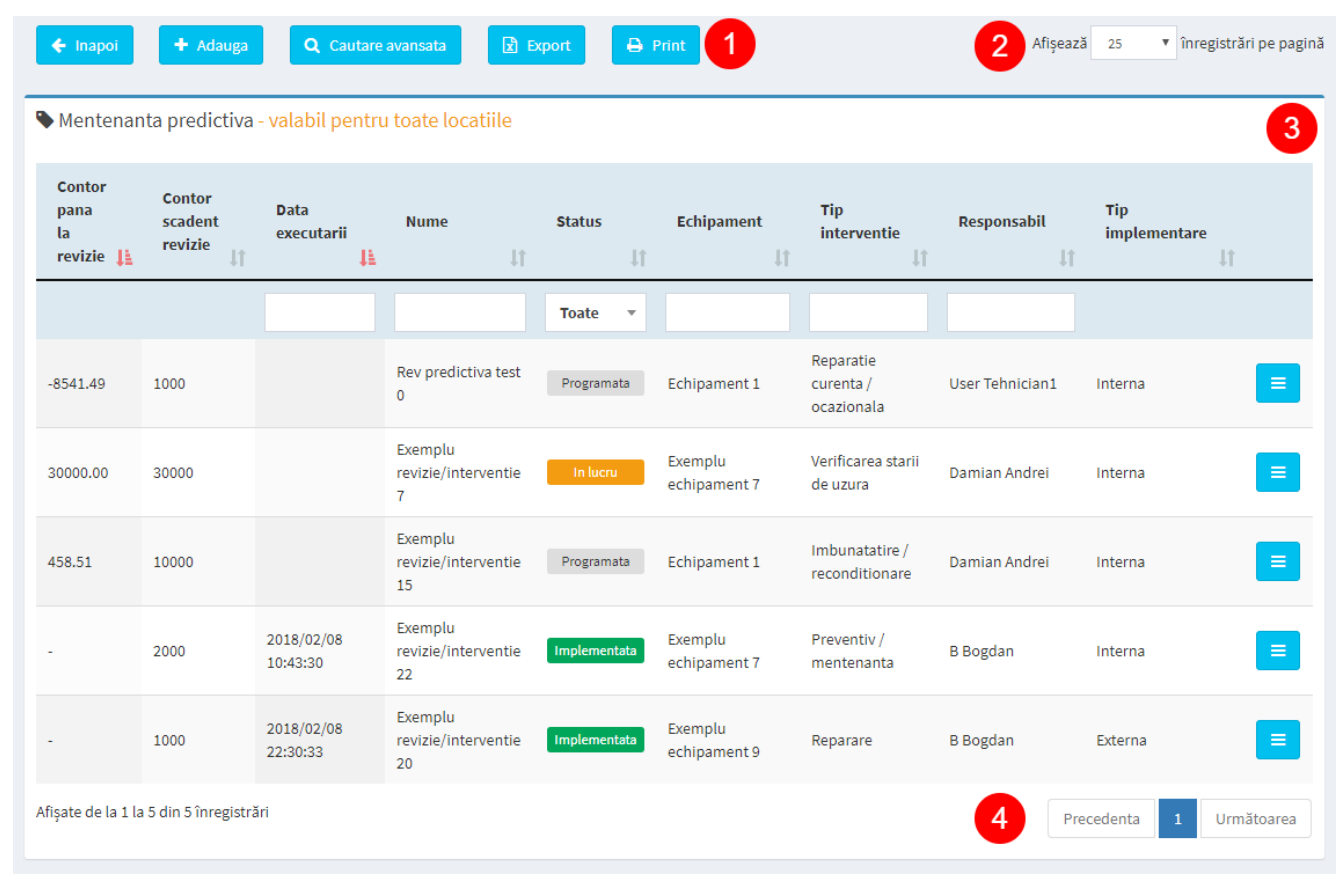

Fig. 3. Function Predictive maintenance of KMR application

The KMR application was designed to manage the maintenance of a wide range of industrial equipment and processes with multiple interconnection possibilities. As such, the application can be connected to the computerized diagnostic software that performs measurements of different sizes on board vehicles, and their maximum and minimum values can be entered as sensor limit values (fig. 4). Based on the comparison of the measured values with the limit values, it will be possible for the specialized personnel to estimate the moment of carrying out a preventive intervention.
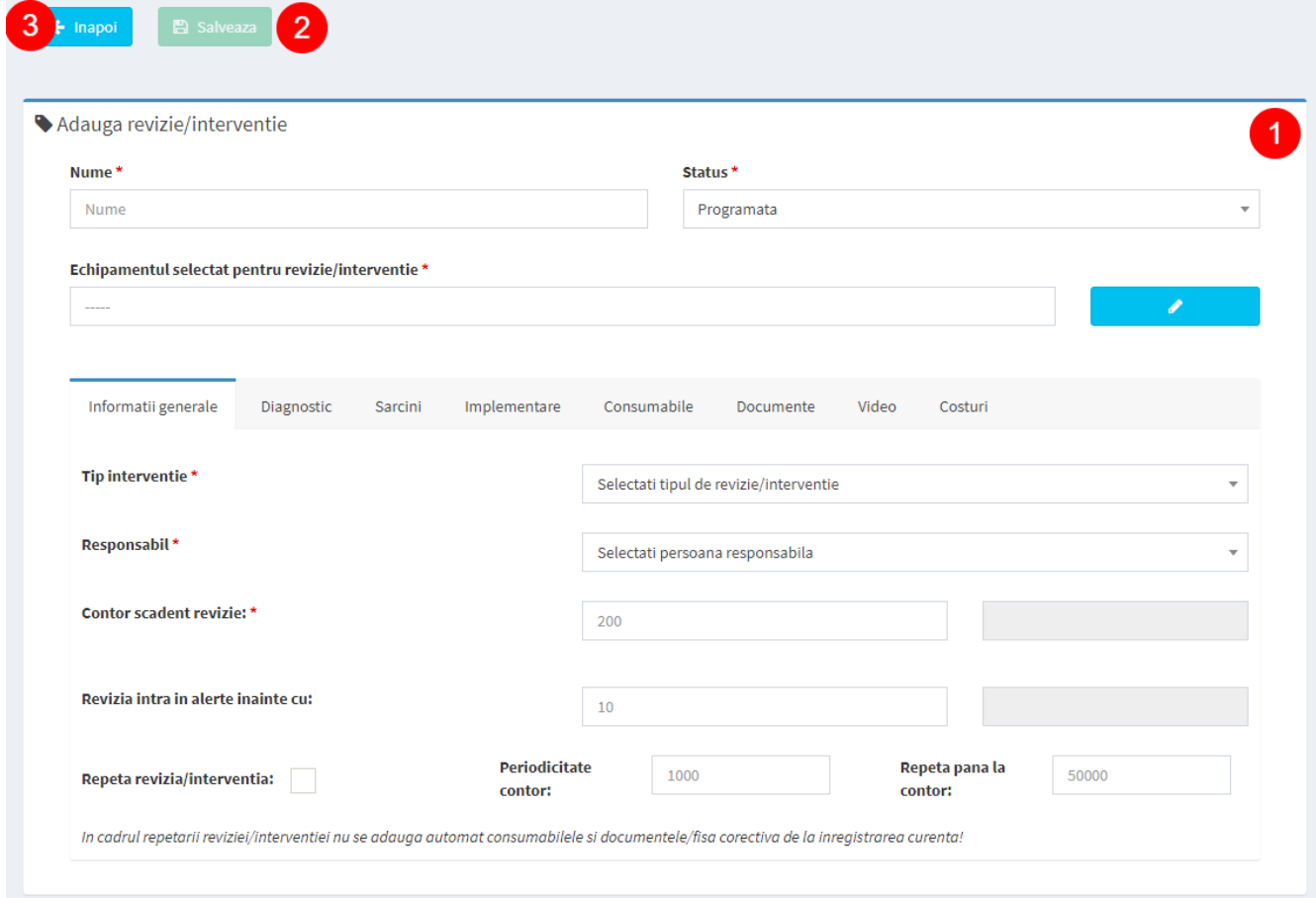

Fig. 4. Function Management sensors of the KMR application 
In this way, the equipment specific to the predictive maintenance of vehicles in table no. 1 will provide results that will be integrated into the application for their processing.

\section{Conclusions}

- predictive maintenance gains increasing importance in ensuring vehicle availability due to its high potential for assessing and estimating the evolution of significant magnitudes in the degradation of the technical condition;

- predictive maintenance develops conceptually due to the constructive evolution of automated and electronically assisted equipment and inter and transdisciplinary knowledge with effect on real-time monitoring and regulation of decision and command systems;

- the emergence of software specialized in the maintenance and safety of technical equipment has made it possible to achieve superior results in the maintenance process and the efficiency of the activities;

- the KMR software enables monitoring and management of maintenance activities between all departments of an organization, as well as other functions related to remote vehicle management on the travel routes;

- the article discusses aspects related to the application of predictive maintenance in the field of motor vehicles and provides some possibilities for operating with the KMR software, leaving it to the staff working with this application to discover its features for optimizing facilities for maintenance services.

Acknowledgements

This article is the first author's research paper on how to work with the Keep the Machine Running (KMR) software for industrial machinery and vehicles.

\section{References}

[1] Burlacu Gabriel, ş.a. Fiabilitatea, mentenabilitatea şi disponibilitatea sistemelor tehnice. Editura MatrixRom, Bucureşti, 2011.

[2] Rădulescu Constanţa, Studii teoretice privind conceptul Total Productive Maintenance. Analele Universităţii “Constantin Brâncuşi” din Târgu Jiu, Seria Inginerie , Nr. 1/2012, pp. 149-159.

[3] Virca Ioan, Dascălu Viorel, Grigoraş Constantin, Research on Improving the Maintenance Activities for Military Vehicles. The $21^{\text {th }}$ international conference „The Knowledge Based Organization”, Conference Proceedings 3, Land Forces Academy Publishing House, 11-13 june 2015, Sibiu, pp. 248-255, ISSN 1843-6722.

[4] Virca, Ioan, Mănescu Gabriel, Prunescu Gheorghe, Analysis Regarding the Maintenance Efficiency of Military Technical Systems. The $21^{\text {th }}$ international conference ,The Knowledge Based Organization", Conference Proceedings 3, Land Forces Academy Publishing House, 11-13 june 2015, Sibiu, pp. 256-261, ISSN 1843-6722.

[5] http://www.arc.ro/fascicole/

[6] Manual de utilizare KMR, https://www.mykmr.ro/demo/kmr3.0/help/documentatie/

[7] https://manwinwin.com/en/maintenance-management-software/ 